CHROM. 3392

\title{
CHROMATOGRAPHIC RESOLUTION OF A RACEMIC SUBSTANCE ON A MICROPOROUS RESIN
}

TIMOTHY S. STEVENS AND JOHN A. LOTT

University of Michigan, Flint College, Flint, Michigan 48503 (U.S.A.)

(Received January 9th, 1968)

SUMMARY

A microporous polymer of ethylvinylbenzene and clivinylbenzene was chloromethylated and then aminated with $(-)-\alpha$-phenethylamine to produce an optically active weak-base ion-exchange resin. Partial resolutions of mandelic acid were achieved with water and methanol as solvents but no resolution was observed with ethanol or chloroform. Some postulations are presented to explain the limited resolution that was observed and the structure of a more effective resolving resin is proposed.

INTRODUC'TION

Considerable progress has been reported recently on the resolution of diastereoisomers by chromatographic methods. Racemic amino acids ${ }^{1-5}$, alcohols ${ }^{5-7}$, and annines 8,0 have been resolved by gas chromatography (GC) via volatile diastereoisomers on inactive substrates. Diastereoisomeric dipeptides have been separated by thin-layer chromatography $\mathbf{1 0}^{\mathbf{0}}$ and esters of racemic sec.-butanol with active lactic or mandelic acid were resolved on Dowex-5011. Reports on the more difficult separation of enantiomers on active substrates have also appeared. Racenic amino acids have been resolved by $\mathrm{GC}$ on capillary ${ }^{12}$ and packed ${ }^{13}$ columns, and mandelic acid has been resolved partially on a variety of active substrates by liquid column chromatography (LC) $^{14-17}$. Also, $\alpha$-olefins have been resolved on optically active vinyl polymers ${ }^{18}$, and coordination compounds of $\mathrm{Ni}$ (II) on cellulose by $\mathrm{LC}^{10}$.

The GC separation of cliastereoisomers or enantiomers is so much faster than LC, so that for the analytical determination of optical purity, GC is the method of choice. But for preparative purposes, LC of diastereoisomers or enantiomers is superior since much larger samples can be chromatographed at one time.

In LC, very long columns are usually avoided due to the enormous pressures necessary to force the liquid through the column. It was felt that a column of a microporous resin, as described by Holnis ${ }^{20}$, would show a smaller pressure drop than a conventional ion-exchange resin, and hence permit LC with very long columns. Active (-)- $\alpha$-phenethylamine was chosen to be incorporated into the polymer since the asymmetric carbon is adjacent to the exchanging site and the carbon is surrounded by fairly large groups to limit the number of conformations. A weak-base resin was felt to be superior to a strong-base resin prepared earlier ${ }^{15}$ since closer approach to the 
asymmetric carbon by the isomers of the racemic substance being chromatographed was shown to be possible using Fisher-Hirschfelder models.

EXPERIMENTAL

Synthesis of the optically active resin,

$$
-\mathrm{C}_{0} \mathrm{HI}_{4}-\mathrm{CHT}_{2}-\mathrm{NH}-\underset{\mathrm{CH}_{3}}{\mathrm{CH}-\mathrm{C}_{0} \mathrm{H}_{5}}
$$

Chloromethylation. To a slurry of $8 \mathrm{~g}$ of Porapals $\mathrm{Q}^{*}, 8 \mathrm{O}-\mathrm{xoo}$ mesh, and $\mathrm{I} 2 \mathrm{~g}$ of chloromethyl methylether, $\mathrm{I} 2 \mathrm{ml}$ of a Io \%, $\mathrm{v} / \mathrm{v}$ solution of anhydrous stannic chloride in petroleum ether (b.p. $30-60^{\circ}$ ) was added and the mixture agitated well. The reaction mixture was kept at $25^{\circ}$ for $48 \mathrm{~h}$ with occasional mixing. The chloromethylated resin was washed in a small column with Ioo ml of each, dioxane, $45 \%$ water $45 \%$ dioxane ro \% I2 $M \mathrm{HCl}$, $20 \%$ water $70 \%$ dioxane ro $\%$ I2 $M \mathrm{HCl}, 95 \%$ dioxane $5 \%$ methanol, $50 \%$ dioxane $50 \%$ methanol, and with methanol until no further chloride appeared in the effuent. The resin contained 3.00 mmoles of chloride per gram of dry resin as determined by ScHöNIGER's method ${ }^{21}$.

Amination. The optically active amine, (-)- $\alpha$-phenethylamine, was prepared by the procedure of THEILACKER AND WINIKLER ${ }^{22}$. Six ml of the amine, $[\alpha]_{\mathrm{D}}^{2 \mathrm{r}}=$ $-38.5^{\circ}$ (neat, $d_{4}^{2 \mathrm{I}}=0.952$ ), was added to $3 \mathrm{~g}$ of the chloromethylated resin and the mixture kept at $2^{\circ}$ for $48 \mathrm{~h}$, then at $25^{\circ}$ for $48 \mathrm{~h}$ and finally at $100^{\circ}$ for $\mathrm{I} h$. The recovered excess amine had $[\alpha]_{D}^{ \pm x}=-37.8^{\circ}$ (neat). The aminated resin was slowly washed with $500 \mathrm{ml}$ I $M \mathrm{HCl}, 500 \mathrm{ml}$ I $M \mathrm{NaOH}$, and water until no chloride appeared in the effluent. The weak-base and strong-base capacities were determined as described elsewhere ${ }^{15}$. The weak-base capacity was 2.26 mmoles per gram of dry, free-amine form resin. No strong-base capacity was found. The problem of extra cross linking to form quaternary nitrogens as reported previously ${ }^{\mathbf{1 5}}$ had been avoided.

Chromatography. In the experiments with chloroform, the optically active resin was slurried into the column with benzene. A glass wool plug was placed on top of the bed, and the benzene washed out with chloroform. In the other experiments, the resin was slurried into the column with the solvent used. The column was fitted with a reservoir above it, and an automatic fraction collector was used to collect $3-6 \mathrm{ml}$ fractions. Frontal chromatography of racemic mandelic acid solutions was carried out. The solution was passed into the column until the optical activity of the fractions after the brealsthrough of the mandelic acid was zero. The non-aqueous fractions were evaporated to dryness with a stream of air at $25^{\circ}$ and the residue dissolved in $6.00 \mathrm{ml}$ of water. In all cases, the manclelic acid content was determined by absorption at $257 \mathrm{~m} \mu$ with a Beckman DB Spectrophotometer and the optical activity with a Perkin-Elmer I4I Polarimeter at the sodium D line. At this point the mandelic acid in the interstitial voids was washed out with the solvent and the exchanged mandelic acid was displaced with o.I $M I$ KOH and collected in one fraction. With the nonaqueous solvents, the fraction was evaporated, dissolved in water, acidified with 0.5 $M \mathrm{HCl}$, and the mandelic acid content and optical activity determined. The same sample and quantity of resin in the free-amine form was used in all the experiments.

* A microporous polymer of ethylvinylbenzene and divinylbenzene. Available from Waters Associates, Inc., $6 r$ Fountain Street, Framingham, Mass. or 70I, U.S.A. 
RESULTS AND DISCUSSION

Table I.

The results of the frontal chromatography experiments are summarized in

TABLE I

DATA FOR TEXTRIMENTS

\begin{tabular}{|c|c|c|c|c|c|}
\hline $\begin{array}{l}\text { Column } \\
\text { height }(I . D \\
=2.5 \mathrm{~mm}) \\
(\mathrm{mm})\end{array}$ & $\begin{array}{l}\text { Concentration } \\
\text { of feed solution } \\
(M)\end{array}$ & $\begin{array}{l}\text { Flowe rate } \\
(\mathrm{cm} / \mathrm{min})\end{array}$ & $\begin{array}{l}\text { Break- } \\
\text { through } \\
\text { volume } \\
(m l)\end{array}$ & $\begin{array}{l}\text { mmoles mandelic acid and } \\
\text { optical purity in fraction } \\
\text { at breakthroughe }\end{array}$ & $\begin{array}{l}\text { Sum of } \\
\text { measured } \\
\alpha^{\prime} s, I d m \\
\text { cell }\end{array}$ \\
\hline Iodo: & $0.0 I^{a}$ & 0.60 & 150 & 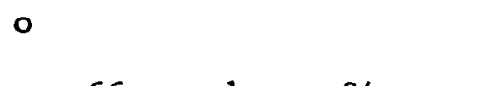 & $\begin{array}{l}0.000 \\
0.000^{r}\end{array}$ \\
\hline 880 & $0.0 I^{b}$ & 2.0 & 138 & 0.0466 mmoles $5.7 \%$ pure & $\begin{array}{l}-0.0{ }^{4} \\
+0.0 I^{2}\end{array}$ \\
\hline 880 & $0.023^{c}$ & 2.2 & 40 & 0.0404 mmoles $3.9 \%$ pure & $\begin{array}{c}+0.0 I_{4} \\
-0.0 I^{2}\end{array}$ \\
\hline 880 & $0.0 I^{d}$ & I.O & $5^{B}$ & 0 & $\begin{array}{l}0.000 \\
0.000^{t}\end{array}$ \\
\hline
\end{tabular}

a In $\mathrm{CHCl}_{3}$.

- In $\mathrm{H}_{2} \mathrm{O}$ containing $0.1 \mathrm{ml}$ Zephiran per liter (as an antibacterial - a $\mathrm{I} 7 \%$ solution of alkyldimethylbenzylammonium chlorides, Winthrop Laboratories, 90 Park Ave., New York, N. Y., U.S.A.).

c In $\mathrm{CH}_{3} \mathrm{OH}$.

d In $\mathrm{C}_{\mathbf{g}} \mathrm{H}_{5} \mathrm{OH}$ distilled from o.or $M$ alcoholic $\mathrm{K} O \mathrm{OH}$.

- Based on $[\alpha]_{D}^{20}=150$ of mandelic acida3.

I Of mandelic acid displaced from the column with o.I $M$ KOH.

B Appeared after interstitial volume.

A to to $30 \mathrm{~cm}$ head was sufficient to produce the listed flow rates. Apparently the microporous structure of the beads was not affected during the synthesis. The optical activity of the fractions went to zero shortly after the breakthrough. With chloroform, water and methanol, the concentration of mandelic acid at the breakthrough went from near zero to the concentration of the feed solution in to $\mathrm{ml}$ or less. This indicates rapid reaction in the column.

No resolution was observed in chloroform perhaps due to a slow equilibration between the mandelate ions held on the resin and the mandelic acid in solution. A cliange in the shape of the solvated mandelic acid isomers in water and methanol and/or a change in the shape of the solvated resin group may account for the reversal in the sign of the rotation of the mandelic acid which appeared at the breakthrough.

The unusual results with ethanol as the solvent are being investigated further. The experiments were performed in the order listed in Table I. Decomposition of the resin did not occur since the apparent capacity to mandelic acid in water was rechecked, and it agreed with the earlier experiments with water. A much longer column would have improved the resolutions observed. Considerable quantities of partly resolved mandelic acid could be prepared with columns of greater length and/or cross-sectional area.

If the difference in interaction between the two isomers and the active sorbent 
could be increased, the resolution would be improved. The absolute configurations of $D(-)$ - and $L(+)-$ mandelic acid are ${ }^{24}$ :

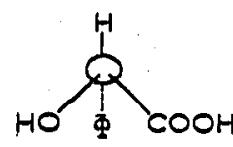

$D(-)$ or 5

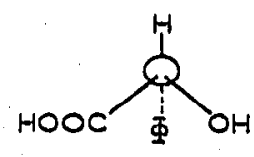

$L(+)$ or $R$

The absolute configuration about the asymmetric carbon in the resin is ${ }^{\mathbf{2 5}}$ (M refers to the resin matrix):

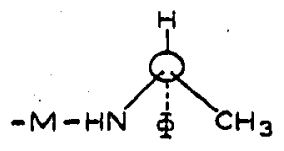

$L(-)$ or $R$

For resolution to occur, the resin group and the mandelic acid must contact each other at at least three points ${ }^{26}$. Assuming that the phenyl groups of the resin and acid are in contact, then the mandelate form of the resin can have four possible configurations :

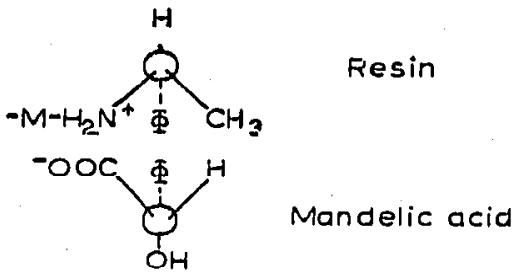

$D(-)$

Case (1)

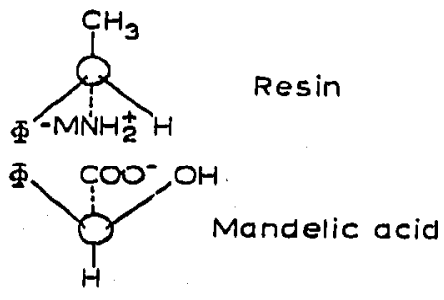

$D(-)$

Case (3)

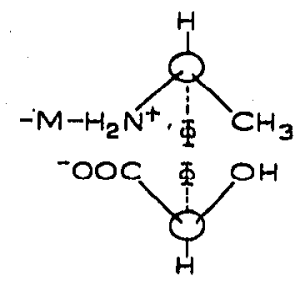

$L(+)$

Case (2)

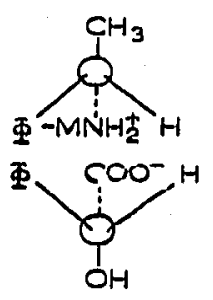

$L(+)$

Case (4) In cases $(I)$ and $(2)$, any discrimination between the two mandelic acid isomers
rests on a difference in the interaction between $\mathrm{CH}_{3}$ and $\mathrm{H}$, and $\mathrm{CH}_{3}$ and $\mathrm{OH}$. $\mathrm{A}$ large difference in interaction could hardly be expected since the difference in the van der Waals interactions is very small. In cases (3) and (4), a difference in the interaction must be due to the $\mathrm{H}$ and $\mathrm{OH}$, and the $\mathrm{H}$ and $\mathrm{H}$ interactions. A large difference in the interactions here could also not be expected for the reason given.

If the methyl group on the active carbon of the resin were replaced with a 
carboxylic acid group, a more discriminating resin may result since the difference in the interaction in cases (I) and (2) would then be due to $\mathrm{H}$ and $\mathrm{COOH}$ versus $\mathrm{OH}$ and COOH. Hydrogen bonding is possible in case (2). Cases (3) and (4) would be unchanged. $A$ resin with this structure could be prepared by incorporating active $\alpha$-phenylglycine into a polymer matrix. A resin of this type should be effective in resolving mandelic acid and perhaps racemic amino acids. The resin could be used as a weakbase or weak-acid ion-exchange resin by adjusting the $\mathrm{pH}$ of the feed solution appropriately. An investigation of this resin is being carried out.

\section{ACINNOWLEDGEMENT}

This work was supported in part by a grant from the Horace H. Rackham School of Graduate Studies of the University of Michigan.

\section{REFERENCES}

I E. Gil-Av, R. Charles and G. Fischer, J. Chromatog., I7 (I965) 408.

2 B. Haipern and J. W. Westley, Chem. Commun., (I965) 247.

3 B. Halpern and J. W. Westley, Chem. Commun., (I966) 34.

4 B. Halpern and J. W. Westlex, Biochem. Biophys. Res. Commun., ig (1965) 361.

5 E. Gil-Av, R. Charles-Sigler, G. Fischer aNd D. NuRoi, J. Gas Chromatog., 4 (I966) $5 \mathrm{x}$.

6 B. L. Irarger, R. L. Stern, H. C. Rose and W. Keane, Sixth International Symposium on Gas Chromatography and Associated Techniques, Rome, rg66. Institute of Petroleum, London, 1967.

7 H. C. Rose, R. I. Sterkn and B. L. Karger, Anal. Chem., 38 (r966) 469.

8 E. Gordis, Biochem. Pharmacol., I5 (1966) 2 I24.

9 B. L. Irarger, R. L. Stern, W. IEeane, B. Halpern and J. W. Westley, Anal. Chem., 39 (I967) 228.

to 'T. Wieland and E. Bende, Chem. Ber., 98 (1965) 504.

i I. D. Spitz, H. L. Rothbart and W. Rieman III, J. Chromalog., 29 (I967) 94.

12 E. Gil-Av, B. Ferbush and R. Charles-Sigler, Tetrahedron Letters, (r966) roog.

I3 E. GIL-Av AND B. FEIBUSH, Tetrahedron Letters, (I967) 3345.

I4 G. MANECKE aND W. LAMER, Naluruiss, 52 (I965) 539.

i 5 J. A. LOtT and W. Rieman III, J. Org. Chem., 3 I (Ig66) $56 \mathrm{I}$.

I6 R. E. Leitch, H. L. Rothbart and W. Rimman III, J. Chromalog., 28 (I967) I32.

I 7 G. MaNecise and W. Lamer, Naturwiss., 54 (I967) I $40 \mathrm{~b}$.

is P. Pino, G. Monagnoli, F. Clardelli and E. Benedetti, Mahromol. Chem., 93 (I966) I 58.

Ig L. T. Taylor AND D. H. Busch, J. Am. Chem. Soc., 89 (I967) 5372.

zo O. L. Hollis, Anal. Chem., 38 (1966) 309.

$2 \mathrm{I}$ W. Schöntger, $Z$. Anal. Chem., I8I (I96I) 33.

22 W. Theilaciser and H. G. Winisler, Chem. Ber., 87 (1954) 690.

23 E. Riмвасн, Z. Physih. Chem. (Leipzig), 28 (т899) 252.

24 M. B. Watson and G. W. Youngson, J. Chem. Soc., (r954) 2145.

25 W. LEITAt, Chem. Ber., 64 (I93 I) 2828.

26 C. E. Dalgliesh, $J$. Chem. Soc., (1952) 3940.

J. Chromatog., 34. (I968) $480-484$ 